Artikel Penelitian

\title{
Formulasi dan Stabilitas Nanostructured Lipid Carrier dari Campuran Fraksi Stearin dan Olein Minyak Kelapa Sawit
} Formulation and Stability of Nanostructured Lipid Carrier Prepared from a Mixture of Palm Stearin and Palm Olein

Miftakhur Rohmah $^{12 \star}$, Sri Raharjo ${ }^{2}$, Chusnul Hidayat ${ }^{2}$, Ronny Martien ${ }^{3}$

${ }^{1} J u r u s a n$ Teknologi Hasil Pertanian, Fakultas Pertanian, Universitas Mulawarman, Samarinda

2Jurusan Teknologi Pengolahan Hasil Pertanian, Fakultas Teknologi Pertanian, Universitas Gadjah Mada, Yogyakarta

${ }^{3}$ Departemen Farmasetika, Fakultas Farmasi, Universitas Gadjah Mada, Yogyakarta

*Korespondensi dengan penulis (sraharjo@ugm.ac.id)

Artikel ini dikirim pada tanggal 11 November 2018 dan dinyatakan diterima tanggal 25 Februari 2019. Artikel ini juga dipublikasi secara online melalui https://ejournal2.undip.ac.id/index.php/jatp. Hak cipta dilindungi undang-undang. Dilarang diperbanyak untuk tujuan komersial.

Diproduksi oleh Indonesian Food Technologists ${ }^{\circledR}$ (C2019

\begin{abstract}
Abstrak
Nanostructured Lipid Carriers (NLC) adalah sistem pembawa berbasis lipida yang menggunakan kombinasi matriks berupa lipid padat dan cair yang distabilkan dengan penambahan surfaktan. NLC ini dikembangkan untuk memfasilitasi dispersi senyawa bioaktif hidrofobik dalam sistem hidrofilik. Penelitian ini bertujuan untuk mendapatkan formulasi yang tepat untuk menghasilkan dan mengevaluasi stabilitas NLC yang menggunakan fraksi stearin dan fraksi olein minyak kelapa sawit sebagai lipid padat dan cair serta penambahan surfaktan Tween 80 . Tahap pertama penelitian ini adalah membuat formula NLC dengan menggunakan metode High Shear Homogenisasi dan Ultrasonication dengan rasio lipid padat:lipid cair adalah $5: 5 \mathrm{sd} .9: 1 \% \mathrm{~b} / \mathrm{b}$, rasio lipid:surfaktan sebesar 1:3 sd. 1:5\% b/b, dan rasio lipid + surfaktan/air adalah $65,70,80$ dan $85 \%$ b/b. Tahap kedua adalah pengujian stabilitas NLC terhadap sentrifugasi, pemanasan pendinginan, dan penyimpanan pada suhu ruang selama 30 hari. Tahap ketiga yaitu karakterisasi NLC stabil meliputi nilai $\mathrm{pH}$, vikositas, ukuran partikel, indeks polidispersi (PDI), potensial zeta (ZP) dan morfologi NLC. Hasil penelitian menunjukkan NLC stabil pada rasio lipid padat:lipid cair sebesar 5:5 sd. 9:1, rasio lipid:surfaktan adalah 1:4 sd.1:5, rasio lipid + surfaktan/air sebesar $65,70,75$ dan $80 \%$, pH pada kisaran $6,28 \pm 0,15$ sd. $6,44 \pm 0,11$, viskositas sebesar $18,17 \pm 0,29 \mathrm{sd}$. $26,83 \pm 1,61 \mathrm{cP}$, ukuran partikel sebesar $164,3 \pm 6,6$ s.d. $340 \pm 2,0 \mathrm{~nm}$, PDI sebesar $0,20 \pm 0,01$ sd. $0,53 \pm 0,01$, ZP sebesar $(-21,25 \pm 0,01) \mathrm{sd}$. $(-33,70 \pm 0,44) \mathrm{mV}$, dan memiliki morfologi bulat. Kesimpulannya, informasi tentang formulasi dan stabilitas NLC sebagai sistem pembawa senyawa bioaktif hidrophobik dapat digambarkan dengan baik.
\end{abstract}

Kata kunci: Nanostructured Lipid Carriers; formulasi; stabilitas; fraksi stearin; fraksi olein

\section{Abstract}

Nanostructured Lipid Carriers (NLC) is a lipid-based delivery system using a matrix of solid and liquid lipids stabilized with surfactants, developed to facilitate the dispersion of hydrophobic bioactive compounds in hydrophilic systems. This study aimed to evaluate the formulation and stability of the NLC delivery system produced using palm stearin and palm olein as solid and liquid lipids as well as Tween 80 surfactant. As initial research, NLC formulations was done using the High Shear Homogenization and Ultrasonication using the ratio of solid:liquid lipids of 5:5 to 9:1\% $\mathrm{W} / \mathrm{w}$, ratio lipid:surfactant as much as $1: 3$ to $1: 5 \% \mathrm{w} / \mathrm{w}$, and lipid+surfactant/water as much as $65,70,80$ and $85 \%$ $W / w$. The second stage was testing the NLC stability against centrifugation, cooling, heating, and storage at room temperature for up to 30 days. The third stage was characterization of stable NLC i.e. pH, viscosity, particle size, polydispersion index (PDI), potential zeta (ZP), and NLC morphology. The results showed stable NLC at the ratio of solid:liquid lipids as much as 5:5 to 9:1, ratio of lipid:surfactant was 1:4 to 1:5, ratio of lipid+surfactant/water was 65, 70,75 and $80 \%$, pH value was $6.28 \pm 0.15$ to $6.44 \pm 0.11$, viscosity $18.17 \pm 0.29$ to $26.83 \pm 1.61 \mathrm{cP}$, particle size was $164.3 \pm 6.6$ to $340 \pm 2.0 \mathrm{~nm}, P D /$ was $0.20 \pm 0.01$ to $0.53 \pm 0.01, Z P(-21.25 \pm 0.01)$ to $(-33.70 \pm 0.44) \mathrm{mV}$, and had spherical morphology. As conclusion, the design of NLC as a delivery system for bioactive compounds was presented succesfully.

Keywords: Nanostructured Lipid Carriers; formulation; stability; palm stearin; palm olein

\section{Pendahuluan}

Nanoteknologi telah banyak dikembangkan dan salah satunya adalah aplikasi pada sistem pembawa guna memberikan perlindungan dan sebagai transfer senyawa bioaktif hidrofobik maupun hidrofilik sehingga kemampuan stabilitas dan bioavailabilitasnya dapat ditingkatkan (McClements, 2017). Salah satu sistem pembawa berbasis lipid yang berpotensi untuk senyawa hidrofobik adalah NLC atau Nanostructured Lipid
Carriers (Tamjidi et al., 2013). Sistem NLC merupakan pengembangan sistem pembawa berbasis Solid Lipid Nanoparticle yang memiliki kekurangan karena tingkat difusi yang rendah sehingga waktu rilis menjadi panjang, dengan kandungan air yang tinggi yang mengakibatkan terjadinya kristalisasi pada sistem, dan pada akhirnya sehingga mengurangi kelarutan senyawa bioaktif dan terjadinya burst release atau rilis dengan tiba-tiba (Müller et al., 2002). 
Sistem NLC memiliki kemampuan enkapsulasi yang tinggi, rilis yang terkontrol, stabil secara termodinamik dan mampu meningkatkan bioavailabilitas senyawa bioaktif (Hung et al., 2011; Tamjidi et al., 2013). Sistem NLC banyak diaplikasikan pada bidang farmasi, karena kemampuannya menghantar obat sampai ke target dan juga mampu mengontrol rilis obat, dengan ukuran partikel nano menyebabkan komponen bioaktif dapat lebih akurat langsung mencapai sel target atau reseptor dalam tubuh (Mohanraj dan Chen, 2007).

Pengembangan NLC yang kompatibel di bidang pangan belum banyak dilakukan, hal tersebut terkait dengan standar keamanan pangan, karena bahan yang digunakan harus food grade dan termasuk dalam kategori GRAS (Generally Recognized as Safe). Palm Stearin (PS) dan Palm Olein (PO) merupakan jenis lipid yang dapat dikembangkan sebagai bahan formulasi NLC karena merupakan jenis lipid yang edible dengan kompatibilitas yang baik, memiliki kandungan asam lemak dengan jenis yang hampir sama, namun berbeda pada proporsinya. PS mengandung asam miristat $1-2 \%$, asam palmitat berkisar antara $47-74 \%$, asam stearat 4$6 \%$, asam oleat $16-37 \%$ dan asam linoleat $3-10 \%$, sedangkan PO mengandung asam lemak palmitat dan oleat dengan jumlah yang hampir sama, yaitu sekitar $40 \%$, dan asam lemak stearat dalam jumlah kecil (Pantzaris dan Sue, 2017).

Jenis lipid dan komposisi bahan sangat berpengaruh terhadap karakteristik fisikokimia formulasi NLC, seperti ukuran partikel, indeks polidispersi atau $\mathrm{PDI}$, zeta potensial atau ZP, viskositas, efisiensi enkapsulasi yang nantinya dapat menentukan efektifitas sistem NLC dalam membawa senyawa bioaktif (Shah et al., 2016). Surfaktan Tween 80 yang digunakan pada formulasi NLC merupakan salah satu surfaktan food grade, bersifat larut air, jenis surfaktan nonionik dengan nilai Hydrophile Lipophile Balance (HLB) $=15$ yang tergolong bersifat aman dan tidak menimbulkan toksik, dan dinilai kompatibel dengan bahan yang diemulsi seperti yang terdapat pada sistem pembawa NLC (Prieto dan Calvo, 2013).

Penggunaan bagian dari palm oil sebagai matrik lipid NLC dilaporkan oleh peneliti terdahulu (How et al., 2013) yang memformulasikan hydrogenated palm oil sebagai lipid padat, olive oil sebagai lipid cair dan Twen 80 sebagai surfaktan. Zheng et al. (2013) membuat NLC dengan metode homogenisasi tekanan tinggi dari campuran (palm oil+palm sterain) sebagai lipid padat, dan MCT (Medium Chain Triglycerides) sebagai lipid cair, serta Tween 80 sebagai surfaktan dan hasilnya menunjukkan bahwa NLC memiliki ukuran partikel bervariasi dari 150-350 nm. Namun penelitian penggunaan PS dan PO sebagai matriks lipid NLC yang kompatibel di bidang pangan belum pernah dipublikasikan.

Penelitian ini bertujuan untuk mendapatkan formula sistem pembawa NLC dan mengarakterisasi formula yang stabil. Penelitian ini dapat memberikan informasi sistem NLC yang stabil untuk membawa senyawa bioaktif hidropobik yang dapat diaplikasikan sebagai komponen pangan fungsional.

\section{Materi dan Metode \\ Materi}

Bahan penelitian adalah PS dan PO yang diperoleh dari PT. Smart Tbk Surabaya. Polyoxyethylene sorbitan monooleat (Tween 80) dari Merck (Darmstadt, Jerman) dan aquabidest. Alat penelitian meliputi homogenizer IKA-Ultra-Turax T25 (Staufen, Germany), waterbath, sonikator Branson 1800M (Dietzenbach, Germany), neraca analitik, oven memmert, sentrifuse, US), viskosimeter (Brookfield, US), zetasizer nano (ZS Malvern, UK), Transmission electron miscroscopy (JEM1400 Flash, Japan).

\section{Metode}

Penelitian meliputi produksi NLC, pengujian stabilitas formulasi dan mengarakterisasi formula yang stabil. Uji yang dilakukan pada formula adalah stabilitas terhadap sentrifugasi, pemanasan, pendinginan, penyimpanan suhu ruang, sedangkan pada formula yang stabil meliputi pengukuran $\mathrm{pH}$, viskositas, ukuran partikel, PDI, ZP dan morfologi NLC.

\section{Pembuatan sistem NLC}

NLC disiapkan dengan metode homogenisasi panas menurut metode (Zhu et al., 2015) dengan modifikasi, menggunakan $\mathrm{HSH}$ (high shear homogenizer) Ultra-Turrax T25. NLC pada penelitian ini menggunakan konsentrasi yang bervariasi dari lipid padat (PS), lipid cair (PO), surfaktan (Tween 80) dan air, formula yang digunakan untuk pembuatan NLC disajikan pada Tabel 1. Pembuatan NLC dimulai pertama dengan memanaskan fase lipid yang berupa campuran lipid padat dan lipid cair pada suhu $60^{\circ} \mathrm{C}$. Selanjutnya memanaskan fase air yang berupa surfaktan dan air pada suhu yang sama $60^{\circ} \mathrm{C}$. Campuran tersebut selanjutnya dihomogenisasi dengan $\mathrm{HSH}$ pada kecepatan $24.000 \mathrm{rpm}$ selama 30 menit dengan pengadukan kontinyu dengan menggunakan waterbath untuk mengontrol suhu agar stabil. Selanjutnya formula disonikasi pada $20 \mathrm{kHz}$ selama 15 menit. Formula NLC didinginkan pada suhu ruang $\left(27 \pm 2^{\circ} \mathrm{C}\right)$.

Tabel 1. Komposisi formulasi NLC dengan menggunakan konsentrasi yang bervariasi dari lipid padat (PS), lipid cair (PO), surfaktan (Tween 80), dan air

\begin{tabular}{lll}
\hline Bahan & Fungsi & $\begin{array}{l}\text { Konsentrasi } \\
\text { Formula }(\% \mathrm{~b} / \mathrm{b})\end{array}$ \\
\hline \multirow{2}{*}{ Lipid padat:lipid cair } & Fase lipid & $\begin{array}{l}9: 1,8: 2,7: 3, \\
6: 4 ; 5: 5\end{array}$ \\
\multirow{2}{*}{ Tween 80} & Surfaktan & $\begin{array}{l}1: 1,1: 2,1: 3, \\
1: 4,1: 5\end{array}$ \\
\multirow{2}{*}{ Aquabidest } & Fase air & $\begin{array}{l}65 ; 70,75,80, \\
\end{array}$ \\
\hline
\end{tabular}

\section{Uji Stabilitas Formulasi NLC}

Uji stabilitas meliputi uji stabilitas yang dipercepat dan stabilitas jangka panjang. Pada uji stabilitas yang dipercepat, sampel NLC sebanyak $15 \mathrm{ml}$ ditempatkan dalam tabung tertutup dan disentrifugasi (6000 rpm, 15 menit), lalu dilakukan pemanasan $\left(105^{\circ} \mathrm{C}\right)$ dalam oven selama 12 jam dan pendinginan $\left(4^{\circ} \mathrm{C}\right)$ selama 12 jam. Uji 
stabilitas jangka panjang dilakukan dengan menyimpan sampel NLC pada suhu ruang $\left(27 \pm 2^{\circ} \mathrm{C}\right)$, selama 30 hari.

\section{Karakterisasi NLC Stabil}

Terhadap NLC yang stabil selanjutnya dilakukan karakterisasi dengan mengukur nilai $\mathrm{pH}$ dengan $\mathrm{pH}$ meter, viskositas dengan viskosimeter dengan menggunakan spindle 61 , kecepatan $60 \mathrm{rpm}$ pada suhu $25^{\circ} \mathrm{C}$. Ukuran partikel, PDI, dan ZP diukur dengan teknik Dynamic Light Scattering menggunakan photon correlation spectroscopy pada suhu $\left(25^{\circ} \mathrm{C}\right)$ dengan cara sampel diencerkan sebanyak 10 kali dengan aquabidest dan di observasi (Lv et al., 2016).

Analisis morfologi NLC

Morfologi NLC diamati dengan TEM, dengan cara satu tetes sampel tersebar pada grid tembaga 200-mesh dilapisi dengan membran karbon, foto TEM diambil menggunakan beberapa perbesaran untuk mendapatkan gambar yang tepat (Liu et al., 2014).

\section{Uji Statistik}

Data yang ditampilkan adalah nilai rata-rata dari 3 ulangan dengan standar deviasi. Data dianalisis menggunakan ANOVA pada taraf 0,05 dan untuk menguji perbedaan antar perlakuan dilakukan uji DMRT pada taraf signifikansi yang sama.

\section{Hasil dan Pembahasan}

NLC Hasil Preparasi

Bahan yang digunakan pada formulasi NLC pada penelitian ini adalah food grade. Penelitian ini bertujuan meningkatkan penggunaan lipid nabati hasil fraksinasi dari minyak kelapa sawit berupa lipid padat PS dan lipid cair PO yang mengandung asam lemak yang edible. PS dan PO biasa digunakan sebagai bahan dalam pengolahan makanan, sehingga keamanannya lebih terjamin. Penggunaan lipid padat berfungsi mengurangi terjadinya proses difusi molekul pada NLC, yang berakibat pada peningkatan retensi dan stabilitas kimia dari komponen bioaktif, sedangkan lipid cair berfungsi meningkatkan efisiensi enkapsulasi senyawa bioaktif (Weiss et al., 2008). Lipid PS dan PO memiliki kompatibilitas yang baik karena diperoleh dari sumber yang sama, sehingga penggabungan PS dan PO dalam sistem NLC menunjukkan keberhasilan formula NLC. Hal ini seiring dengan penelitian Zheng, et al. (2013) yang memproduksi NLC dari minyak minyak sawit dengan fraksi stearin dan beberapa jenis lipid lain yaitu hydrogenated sunflower oil, hydrogenated rapeseed oil, soys oil, dan Medium Chain Triglycerides (MCT dengan campuran $60 \%$ caprylic dan $40 \%$ capric acids) dan Tween 80, menghasilkan NLC yang stabil dengan ukuran partikel 150-350 $\mathrm{nm}$.

NLC disiapkan menggunakan metode homogenisasi panas dengan menggunakan $\mathrm{HSH}$ yang dilanjutkan dengan sonikasi. Penggunaan $\mathrm{HSH}$ telah diketahui dapat menghasilkan formula NLC dengan ukuran nano (Severino et al., 2012; Bagherpour et al., 2017). HSH bekerja dengan menggesek dan memecah partikel pada campuran antara lipid, surfaktan dan air pada suhu $5-10^{\circ} \mathrm{C}$ di atas titik lebur lipid untuk membentuk emulsi. Emulsi yang dihasilkan kemudian disonikasi untuk membantu menurunkan ukuran partikel (Babazadeh, et al., 2017). Keberhasilan sistem NLC ini, selain ukuran partikel yang diinginkan dapat tercapai, juga diperoleh NLC yang cukup stabil yang ditunjukkan tidak terjadinya pemisahan fase dan creaming (Hung et al., 2011; Fathi, et al., 2018). Stabilitas fisikokimia dan fungsional dari sistem pembawa yang berbasis emulsi dapat dikontrol dengan merancang kondisi dan komposisi formulasi sehingga menghasilkan NLC stabil dengan target ukuran partikel nano (Lesmes dan McClements, 2009; McClements, 2010).

Tabel 3. Nilai pH dan viskositas formula NLC stabil

\begin{tabular}{|c|c|c|}
\hline Formulasi & $\mathrm{pH}$ & Viskositas \\
\hline $\mathrm{F} 2 \mathrm{~A}$ & $6,32 \pm 0,04$ & $18,83 \pm 0,76$ \\
\hline F2B & $6,37 \pm 0,06$ & $18,33 \pm 0,58$ \\
\hline $\mathrm{F} 2 \mathrm{C}$ & $6,42 \pm 0,09$ & $18,67 \pm 0,58$ \\
\hline F2D & $6,28 \pm 0,06$ & $19,00 \pm 1,00$ \\
\hline F3A & $6,28 \pm 0,15$ & $18,50 \pm 0,50$ \\
\hline F3B & $6,35 \pm 0,10$ & $18,83 \pm 0,58$ \\
\hline $\mathrm{F} 3 \mathrm{C}$ & $6,44 \pm 0,17$ & $18,83 \pm 0,29$ \\
\hline F3D & $6,34 \pm 0,04$ & $18,67 \pm 0,58$ \\
\hline F5A & $6,39 \pm 0,07$ & $22,17 \pm 5,92$ \\
\hline F5B & $6,35 \pm 0,07$ & $22,33 \pm 6,21$ \\
\hline F5C & $6,29 \pm 0,05$ & $19,33 \pm 0,76$ \\
\hline F5D & $6,34 \pm 0,02$ & $20,00 \pm 1,32$ \\
\hline F6A & $6,34 \pm 0,10$ & $18,17 \pm 0,29$ \\
\hline F6B & $6,37 \pm 0,04$ & $18,83 \pm 0,29$ \\
\hline F6C & $6,33 \pm 0,06$ & $18,67 \pm 0,76$ \\
\hline F6D & $6,32 \pm 0,04$ & $19,00 \pm 2,00$ \\
\hline F8A & $6,31 \pm 0,05$ & $22,33 \pm 1,61$ \\
\hline F8B & $6,26 \pm 0,10$ & $21,50 \pm 1,80$ \\
\hline $\mathrm{F} 8 \mathrm{C}$ & $6,33 \pm 0,01$ & $21,17 \pm 2,47$ \\
\hline F8D & $6,39 \pm 0,08$ & $20,17 \pm 1,76$ \\
\hline F9A & $6,42 \pm 0,05$ & $22,33 \pm 2,08$ \\
\hline F9B & $6,41 \pm 0,07$ & $21,67 \pm 2,08$ \\
\hline F9C & $6,34 \pm 0,04$ & $20,67 \pm 2,08$ \\
\hline F9D & $6,31 \pm 0,08$ & $20,67 \pm 2,89$ \\
\hline F11A & $6,41 \pm 0,06$ & $26,00 \pm 2,65$ \\
\hline $\mathrm{F} 11 \mathrm{~B}$ & $6,30 \pm 0,05$ & $24,00 \pm 2,65$ \\
\hline F11C & $6,41 \pm 0,01$ & $24,00 \pm 3,61$ \\
\hline F11D & $6,38 \pm 0,01$ & $25,00 \pm 4,00$ \\
\hline F12A & $6,41 \pm 0,05$ & $26,83 \pm 1,61$ \\
\hline F12B & $6,44 \pm 0,11$ & $25,83 \pm 1,26$ \\
\hline F12C & $6,35 \pm 0,04$ & $24,67 \pm 3,01$ \\
\hline F12D & $6,35 \pm 0,02$ & $24,83 \pm 3,82$ \\
\hline
\end{tabular}

Keterangan: Kode formula NLC stabil (rasio lipid padat:lipid cair (6:4 s.d 9:1); rasio lipid:surfaktan (1:3-1:4); rasio lipid+surfaktan/air (65,70, 87, dan $80 \%)$

Stabilitas NLC

Uji stabilitas dilakukan untuk mendeteksi kemungkinan perubahan selama penyimpanan (Okonogi dan Riangjanapatee, 2015). Ketidakstabilan fisik sistem pembawa yang berbasis emulsi dapat dideteksi dengan melihat terjadinya creaming, pemisahan fase minyak atau sedimentasi komponen yang memiliki densitas tinggi. Hal tersebut dapat dilihat ketika NLC telah dikenai perlakuan sentrifugasi, pemanasan, ataupun pendinginan (Liu et al., 2014). 
Tabel 2. Hasil uji stabilitas formula NLC terhadap sentrifugasi, pemanasan dan pendinginan, dan penyimpanan pada suhu ruang selama 30 hari

\begin{tabular}{|c|c|c|c|c|c|c|}
\hline \multirow[b]{2}{*}{ Formulasi } & \multirow{2}{*}{$\begin{array}{c}\text { Rasio } \\
\text { lipid+surfak } \\
\text { tan/air } \\
(\% \mathrm{~b} / \mathrm{b})\end{array}$} & \multirow{2}{*}{$\begin{array}{c}\text { Rasio Lipid } \\
\text { Surfaktan } \\
(\% \mathrm{~b} / \mathrm{b})\end{array}$} & \multirow[b]{2}{*}{$\begin{array}{c}\text { Rasio Lipid } \\
\text { Padat (PS) : } \\
\text { Lipid Cair (PO) } \\
(\% b / b)\end{array}$} & \multicolumn{3}{|c|}{ Pengujian Stabilitas } \\
\hline & & & & $\begin{array}{c}\text { Sentrifugasi } \\
\left(6000 \mathrm{rpm}, 1^{\prime}\right)\end{array}$ & $\begin{array}{l}\text { Pemanasan dan } \\
\text { Pendinginan } \\
\left(105 \& 4^{\circ} \mathrm{C} ;\right. \\
12 \mathrm{jam})\end{array}$ & $\begin{array}{c}\text { Penyimpanan } \\
\text { suhu ruang } \\
\text { (30 hari) }\end{array}$ \\
\hline F1A & & & $6: 4$ & - & - & - \\
\hline F1B & 65 & 1.2 & $7: 3$ & - & - & - \\
\hline $\mathrm{F} 1 \mathrm{C}$ & 65 & $1: 3$ & $8: 2$ & - & - & - \\
\hline F1D & & & $9: 1$ & - & - & - \\
\hline F2A & & & $6: 4$ & $\sqrt{ }$ & $\sqrt{ }$ & $\sqrt{ }$ \\
\hline $\mathrm{F} 2 \mathrm{~B}$ & & & $7: 3$ & $\sqrt{ }$ & $\sqrt{ }$ & $\sqrt{ }$ \\
\hline F2C & 65 & $1: 4$ & $8: 2$ & $\sqrt{ }$ & $\sqrt{ }$ & $\sqrt{ }$ \\
\hline F2D & & & $9: 1$ & $\sqrt{ }$ & $\sqrt{ }$ & $\sqrt{ }$ \\
\hline F3A & & & $6: 4$ & $\sqrt{ }$ & $\sqrt{ }$ & $\sqrt{ }$ \\
\hline F3B & & & $7: 3$ & $\sqrt{ }$ & $\sqrt{ }$ & $\sqrt{ }$ \\
\hline F3C & 65 & $1: 5$ & $8: 2$ & $\sqrt{ }$ & $\sqrt{ }$ & $\sqrt{ }$ \\
\hline F3D & & & $9: 1$ & $\sqrt{ }$ & $\sqrt{ }$ & $\sqrt{ }$ \\
\hline $\mathrm{F} 4 \mathrm{~A}$ & & & $6: 4$ & - & - & - \\
\hline F4B & & & $7: 3$ & - & - & - \\
\hline $\mathrm{F} 4 \mathrm{C}$ & 70 & $1: 3$ & $8: 2$ & - & - & - \\
\hline F4D & & & $9: 1$ & - & - & - \\
\hline F5A & & & $6: 4$ & $\sqrt{ }$ & $\sqrt{ }$ & $\sqrt{ }$ \\
\hline F5B & & & $7: 3$ & $\sqrt{ }$ & $\sqrt{ }$ & $\sqrt{ }$ \\
\hline F5C & 70 & $1: 4$ & $8: 2$ & $\sqrt{ }$ & $\sqrt{ }$ & $\sqrt{ }$ \\
\hline F5D & & & $9: 1$ & $\sqrt{ }$ & $\sqrt{ }$ & $\sqrt{ }$ \\
\hline F6A & & & $6: 4$ & $\sqrt{ }$ & $\sqrt{ }$ & $\sqrt{ }$ \\
\hline F6B & & & $7: 3$ & $\sqrt{ }$ & $\sqrt{ }$ & $\sqrt{ }$ \\
\hline F6C & 70 & $1: 5$ & $8: 2$ & $\sqrt{ }$ & $\sqrt{ }$ & $\sqrt{ }$ \\
\hline F6D & & & $9: 1$ & $\sqrt{ }$ & $\sqrt{ }$ & $\sqrt{ }$ \\
\hline F7A & & & $6: 4$ & - & - & - \\
\hline F7B & & & $7: 3$ & - & - & - \\
\hline F7C & 75 & $1: 3$ & $8: 2$ & - & - & - \\
\hline F7D & & & $9: 1$ & - & - & - \\
\hline F8A & & & $6: 4$ & $\sqrt{ }$ & $\sqrt{ }$ & $\sqrt{ }$ \\
\hline F8B & & & $7: 3$ & $\sqrt{ }$ & $\sqrt{ }$ & $\sqrt{ }$ \\
\hline F8C & 75 & $1: 4$ & $8: 2$ & $\sqrt{ }$ & $\sqrt{ }$ & $\sqrt{ }$ \\
\hline F8D & & & $9: 1$ & $\sqrt{ }$ & $\sqrt{ }$ & $\sqrt{ }$ \\
\hline F9A & & & $6: 4$ & $\sqrt{ }$ & $\sqrt{ }$ & $\sqrt{ }$ \\
\hline F9B & & & $7: 3$ & $\sqrt{ }$ & $\sqrt{ }$ & $\sqrt{ }$ \\
\hline F9C & 75 & $1: 5$ & $8: 2$ & $\sqrt{ }$ & $\sqrt{ }$ & $\sqrt{ }$ \\
\hline F9D & & & $9: 1$ & $\sqrt{ }$ & $\sqrt{ }$ & $\sqrt{ }$ \\
\hline F10A & & & $6: 4$ & - & - & - \\
\hline F10B & & & $7: 3$ & - & - & - \\
\hline F10C & 80 & $1: 3$ & $8: 2$ & - & - & - \\
\hline F10D & & & $9: 1$ & - & - & - \\
\hline F11A & & & $6: 4$ & $\sqrt{ }$ & $\sqrt{ }$ & $\sqrt{ }$ \\
\hline F11B & & & $7: 3$ & $\sqrt{ }$ & $\sqrt{ }$ & $\sqrt{ }$ \\
\hline $\mathrm{F} 11 \mathrm{C}$ & 80 & $1: 4$ & $8: 2$ & $\sqrt{ }$ & $\sqrt{ }$ & $\sqrt{ }$ \\
\hline F11D & & & $9: 1$ & $\sqrt{ }$ & $\sqrt{ }$ & $\sqrt{ }$ \\
\hline $\mathrm{F} 12 \mathrm{~A}$ & & & $6: 4$ & $\sqrt{ }$ & $\sqrt{ }$ & $\sqrt{ }$ \\
\hline $\mathrm{F} 12 \mathrm{~B}$ & & 1.5 & $7: 3$ & $\sqrt{ }$ & $\sqrt{ }$ & $\sqrt{ }$ \\
\hline $\mathrm{F} 12 \mathrm{C}$ & 80 & $1: 5$ & $8: 2$ & $\sqrt{ }$ & $\sqrt{ }$ & $\sqrt{ }$ \\
\hline F12D & & & $9: 1$ & $\sqrt{ }$ & $\sqrt{ }$ & $\sqrt{ }$ \\
\hline
\end{tabular}

Keterangan: (-) artinya tidak stabil (terjadi pemisahan fase dan atau creaming), $(\sqrt{ })$ artinya stabil (tidak terjadi pemisahan fase dan atau creaming)

Formula NLC mempengaruhi tingkat stabilitas sistem NLC, hasil uji stabilitas disajikan pada Tabel 2.

Formula NLC yang diproduksi berdasarkan perlakuan rasio lipid padat:lipid cair, rasio lipid:surfaktan, dan rasio lipid+surfaktan/air, menghasilkan formula NLC yang stabil terhadap sentrifugasi, pemanasan, pendinginan, dan penyimpanan adalah formula F2, F3, F5, F6, F8, F9, F11, dan F12 dengan rasio lipid:surfaktan 1:4 dan 1:5. Rasio lipid:surfaktan lebih dominan mempengaruhi stabilitas sistem, hal tersebut disebabkan karena surfaktan berperan penting dalam menstabilkan sistem berbasis minyak. Surfaktan mampu menurunkan tegangan permukaan dengan cepat mencegah agregasi dan rekristalisasi partikel, sehingga dapat menstabilkan tegangan antar muka (Han et al., 2008; McClements dan Rao, 2011). Peneliti lain (Witayaudom dan Klinkesorn, 2017; Karn-orachai et al., 2014) juga melaporkan konsentrasi dan komposisi surfaktan dapat mempengaruhi stabilitas sistem NLC. Menurut Ziani, et al., (2012) rasio surfaktan:minyak dan juga jenis minyak dapat mempengaruhi stabilitas sistem dispersi koloid. Sistem pembawa berukuran makroskopis dapat terbentuk pada rasio lipid:surfaktan diatas 1:2, namun juga dapat dipengaruhi metode pembuatan yang digunakan. Formulasi sistem pembawa berbasis lipid dapat dengan mudah terbentuk dengan 
Tabel 4. Hasil analisa ukuran partikel, PDI dan ZP pada formulasi NLC stabil pada pengujian 0 dan 30 hari

\begin{tabular}{|c|c|c|c|c|c|c|}
\hline \multirow[b]{2}{*}{ Formulasi } & \multicolumn{3}{|c|}{0 hari } & \multicolumn{3}{|c|}{30 hari } \\
\hline & $\begin{array}{c}\text { Ukuran } \\
\text { Pertikel (nm) }\end{array}$ & PDI & $\mathrm{ZP}(\mathrm{mV})$ & $\begin{array}{c}\text { Ukuran } \\
\text { Pertikel }(\mathrm{nm})\end{array}$ & PDI & $\mathrm{ZP}(\mathrm{mV})$ \\
\hline F2A & $164,33 \pm 6,6^{a}$ & $0,21 \pm 0,01^{a}$ & $-22,27 \pm 0,67^{a}$ & $180 \pm 1,41^{a}$ & $0,28 \pm 0,05^{b}$ & $-22,90 \pm 0,14^{a}$ \\
\hline $\mathrm{F} 2 \mathrm{~B}$ & $175,33 \pm 4,6^{a}$ & $0,21 \pm 0,01^{a}$ & $-21,47 \pm 1,35^{a}$ & $201 \pm 2,00^{a}$ & $0,22 \pm 0,02^{\mathrm{a}}$ & $-23,60 \pm 1,04^{a}$ \\
\hline $\mathrm{F} 2 \mathrm{C}$ & $174,33 \pm 4,7^{a}$ & $0,23 \pm 0,01^{a}$ & $-22,80 \pm 2,00^{a}$ & $203,6 \pm 4,51^{a}$ & $0,34 \pm 0,02^{c}$ & $-24,57 \pm 0,59^{a}$ \\
\hline F2D & $283,50 \pm 7,7^{c}$ & $0,22 \pm 0,02^{a}$ & $-21,25 \pm 0,07^{a}$ & $305,3 \pm 6,1$ & $0,24 \pm 0,02^{a}$ & $-24,80 \pm 0,26^{a}$ \\
\hline F3A & $167,50 \pm 3,5^{a}$ & $0,33 \pm 0,01^{b}$ & $-27,45 \pm 0,49^{b}$ & $184 \pm 7,07^{a}$ & $0,35 \pm 0,04^{c}$ & $-29,30 \pm 0,72^{b}$ \\
\hline F3B & $173,67 \pm 4,0^{a}$ & $0,38 \pm 0,01^{b}$ & $-26,93 \pm 0,23^{b}$ & $182,3 \pm 2,52^{a}$ & $0,38 \pm 0,02^{c}$ & $-29,63 \pm 0,57^{b}$ \\
\hline $\mathrm{F} 3 \mathrm{C}$ & $272,67 \pm 6,6^{b c}$ & $0,37 \pm 0,02^{b}$ & $-30,63 \pm 1,29^{b}$ & $306 \pm 5,29$ & $0,34 \pm 0,02^{c}$ & $-32,47 \pm 0,60^{b}$ \\
\hline F3D & $192 \pm 4,3^{a}$ & $0,37 \pm 0,02^{b}$ & $-29,50 \pm 0,53^{b}$ & $197,3 \pm 7,2^{b}$ & $0,36 \pm 0,01^{c}$ & $-31,67 \pm 1,08^{b}$ \\
\hline F5A & $276,50 \pm 6,3^{b c}$ & $0,29 \pm 00,1^{\mathrm{a}}$ & $-30,95 \pm 1,34^{b}$ & $301,5 \pm 3,5^{c}$ & $0,23 \pm 0,02^{a}$ & $-30,45 \pm 0,49^{b}$ \\
\hline F5B & $304 \pm 6,0^{c}$ & $0,26 \pm 0,01^{a}$ & $-30,23 \pm 2,25^{b}$ & $331,6 \pm 10,2^{c}$ & $0,28 \pm 0,02^{b}$ & $-28,57 \pm 0,61^{b}$ \\
\hline F5C & $291 \pm 4,5^{c}$ & $0,28 \pm 0,01^{a}$ & $-30,53 \pm 0,90^{b}$ & $303,3 \pm 4,16^{c}$ & $0,27 \pm 0,01^{\mathrm{b}}$ & $-30,87 \pm 0,42^{b}$ \\
\hline F5D & $295,33 \pm 7,2^{c}$ & $0,29 \pm 0,01^{a}$ & $-31,43 \pm 0,55^{b}$ & $335 \pm 12,1^{\mathrm{c}}$ & $0,28 \pm 0,03^{b}$ & $-30,33 \pm 0,67^{b}$ \\
\hline F6A & $185,67 \pm 6,6^{a}$ & $0,28 \pm 0,01^{a}$ & $-30,75 \pm 1,20^{b}$ & $192,6 \pm 5,5^{\mathrm{a}}$ & $0,31 \pm 0,01^{b c}$ & $-31,45 \pm 2,19^{b}$ \\
\hline F6B & $192,00 \pm 4,3^{a}$ & $0,22 \pm 0,01^{a}$ & $-30,83 \pm 2,00^{b}$ & $257,6 \pm 9,02^{b}$ & $0,24 \pm 0,01^{a}$ & $-31,97 \pm 0,71^{b}$ \\
\hline F6C & $220,67 \pm 10,5^{a b}$ & $0,27 \pm 0,03^{a}$ & $-31,23 \pm 1,53^{b}$ & $282,3 \pm 7,6^{b c}$ & $0,29 \pm 0,01^{\mathrm{b}}$ & $-31,77 \pm 1,10^{b}$ \\
\hline F6D & $217,67 \pm 12,0^{a b}$ & $0,31 \pm 0,01^{a b}$ & $-30,44 \pm 1,33^{b}$ & $272 \pm 5,57^{\mathrm{bc}}$ & $0,34 \pm 0,01^{c}$ & $-31,25 \pm 0,49^{b}$ \\
\hline F8A & $175,67 \pm 7,5^{\mathrm{a}}$ & $0,38 \pm 0,02^{c}$ & $-30,00 \pm 0,14^{b}$ & $192,6 \pm 5,51^{a}$ & $0,40 \pm 0,03^{d}$ & $-31,77 \pm 0,49^{b}$ \\
\hline F8B & $282,00 \pm 7^{c}$ & $0,39 \pm 0,01^{c}$ & $-31,77 \pm 1,53^{b}$ & $297,3 \pm 6,4^{\mathrm{bc}}$ & $0,42 \pm 0,01^{d}$ & $-29,97 \pm 0,49^{b}$ \\
\hline $\mathrm{F} 8 \mathrm{C}$ & $290,33 \pm 1,5^{c}$ & $0,47 \pm 0,02^{d}$ & $-32,13 \pm 1,01^{b}$ & $340 \pm 2,0^{c}$ & $0,43 \pm 0,02^{d}$ & $-33,63 \pm 0,40^{b}$ \\
\hline F8D & $245,33 \pm 4,5^{b}$ & $0,49 \pm 0,01^{d}$ & $-31,13 \pm 1,53^{b}$ & $292 \pm 8,49^{b c}$ & $0,38 \pm 0,08^{c}$ & $-30,0 \pm 0,14^{b}$ \\
\hline F9A & $195,00 \pm 5,6^{a}$ & $0,36 \pm 0,04^{c}$ & $-30,90 \pm 0,14^{b}$ & $199,0 \pm 1,41^{a}$ & $0,35 \pm 0,01^{\mathrm{bc}}$ & $-32,03 \pm 0,15^{b}$ \\
\hline $\mathrm{F} 9 \mathrm{~B}$ & $171,67 \pm 10,2^{a}$ & $0,36 \pm 003^{c}$ & $-31,80 \pm 0,85^{b}$ & $205,6 \pm 4,9^{a}$ & $0,39 \pm 0,01^{c}$ & $-33,17 \pm 0,86^{b}$ \\
\hline F9C & $219,33 \pm 10,0 a b$ & $0,40 \pm 0,03^{c d}$ & $-31,83 \pm 1,15^{b}$ & $268,6 \pm 9,6^{b}$ & $0,41 \pm 0,01^{d}$ & $-33,43 \pm 0,38^{b}$ \\
\hline F9D & $272,00 \pm 9,5^{c}$ & $0,42 \pm 0,01^{\mathrm{cd}}$ & $-32,33 \pm 0,45^{b}$ & $305 \pm 5,0^{c}$ & $0,40 \pm 0,03^{d}$ & $-32,47 \pm 0,58^{b}$ \\
\hline $\mathrm{F} 11 \mathrm{~A}$ & $203 \pm 5,6^{\mathrm{ab}}$ & $0,39 \pm 0,03^{c}$ & $-32,85 \pm 0,07^{b}$ & $213 \pm 4,24^{a}$ & $0,41 \pm 0,02^{d}$ & $-33,17 \pm 0,38^{b}$ \\
\hline F11B & $224,33 \pm 5,8^{a b}$ & $0,42 \pm 0,02^{\mathrm{cd}}$ & $-32,70 \pm 1,51^{b}$ & $231,3 \pm 11,5^{b}$ & $0,42 \pm 0,01^{d}$ & $-30,93 \pm 0,92^{b}$ \\
\hline F11C & $273,00 \pm 4,3^{c}$ & $0,53 \pm 0,03^{\ominus}$ & $-30,90 \pm 1,0^{b}$ & $283,6 \pm 5,5^{c}$ & $0,51 \pm 0,02^{\ominus}$ & $-30,90 \pm 1,15^{b}$ \\
\hline F11D & $292,00 \pm 5,0^{c}$ & $0,53 \pm 0,01^{\ominus}$ & $-32,63 \pm 1,80^{b}$ & $319 \pm 2,6^{c}$ & $0,53 \pm 0,02^{\ominus}$ & $-33,70 \pm 0,44^{b}$ \\
\hline $\mathrm{F} 12 \mathrm{~A}$ & $200 \pm 1,4^{\mathrm{ab}}$ & $0,47 \pm 0,01^{d}$ & $-31,47 \pm 0,76^{b}$ & $234,5 \pm 7,7^{b}$ & $0,48 \pm 0,01^{\text {de }}$ & $-31,45 \pm 2,19^{b}$ \\
\hline $\mathrm{F} 12 \mathrm{~B}$ & $246,33 \pm 5,6^{\mathrm{ab}}$ & $0,46 \pm 0,04^{d}$ & $-30,83 \pm 1,37^{b}$ & $260,6 \pm 5,6^{b}$ & $0,47 \pm 0,02^{\mathrm{de}}$ & $-32,47 \pm 0,60$ \\
\hline F12C & $275,00 \pm 7,0^{c}$ & $0,44 \pm 0,02^{\mathrm{cd}}$ & $-33,00 \pm 0,20^{b}$ & $285,3 \pm 5,6^{\text {bc }}$ & $0,46 \pm 0,03^{c}$ & $-32,43 \pm 0,93^{b}$ \\
\hline F12D & $294,33 \pm 4,0^{c}$ & $0,42 \pm 0,02^{c}$ & $-32,37 \pm 0,58^{b}$ & $323 \pm 4,36^{c}$ & $0,44 \pm 0,01^{c}$ & $-33,50 \pm 1,35^{\mathrm{b}}$ \\
\hline
\end{tabular}

Keterangan: angka yang diikuti huruf yang sama pada kolom yang sama menunjukkan tidak berbeda nyata $(p>0.05)$ Keterangan: Kode Formula NLC stabil (rasio lipid padat:lipid cair (6:4 s.d 9:1); rasio lipid:surfaktan (1:3-1:4); rasio (lipid+surfaktan)/air $(65,70,87$, dan $80 \%)$

penggunaan konsentrasi surfaktan yang lebih tinggi (McClements dan Rao, 2011; Salminen et al., 2014).

Pada penelitian ini perlakuan rasio lipid padat:lipid cair dan rasio lipid+surfaktan/air tidak berpengaruh secara nyata terhadap stabilitas sistem NLC yang dihasilkan. Namun lipid sebagai bahan utama dari nanopartikel lipid dapat berpengaruh terhadap kapasitas dan pelepasan senyawa bioaktif yang akan dibawa dalam sistem NLC nantinya. Perlakuan tersebut saling terkait, dimana konsentrasi lipid yang lebih tinggi dapat berpengaruh pada efisiensi enkapsulasi dari senyawa bioaktif yang dibawa. Semakin tinggi konsentrasi lipid, semakin tinggi muatan senyawa bioaktif yang dibawa dan berimplikasi pada efisiensi aplikasi NLC yang diinginkan. Selain itu penggunaan konsentrasi lipid yang lebih tinggi dapat mengurangi komposisi air yang ada dalam sistem, hal ini membantu sistem untuk bisa lebih stabil dalam jangka waktu yang lebih lama dan efisien pada saat proses pembuatan sistem (Tamjidi et al., 2013).

Lipid PS dan PO memiliki titik lebur tidak terlalu jauh yaitu $44 \mathrm{sd} .56^{\circ} \mathrm{C}$ dan $19 \mathrm{sd} .23^{\circ} \mathrm{C}$. Titik lebur tersebut memungkinkan campuran antara PS dan PO dapat membentuk matriks lipid pada sistem NLC, sehingga dapat diperhitungkan campuran PS dan PO optimal untuk mendapatkan formulasi NLC yang dapat direkomendasikan sebagai sistem pembawa komponen bioaktif lipofilik. Pardeike et al. (2011) melaporkan rasio lipid padat:lipid cair 9:1 dapat digunakan dalam sistem NLC, namun rasio yang cukup ideal adalah 7:3. Hal tersebut disebabkan dengan komposisi tersebut komponen bioaktif yang dibawa lebih banyak dan juga dapat mengurangi terjadinya burst release pada bioaktif yang dibawa, karena keberadaan lipid padat mampu memerangkap senyawa bioaktif lebih baik.

\section{$\mathrm{pH}$ dan Viskositas}

Studi stabilitas fisik NLC dilakukan dengan menjaga sistem NLC selama penyimpanan pada suhu ruang. Formula NLC yang stabil dilakukan pengukuran $\mathrm{pH}$ dan viskositas (Tabel 3), ukuran partikel, PDI, ZP yang dianalisis pada hari 0 dan 30 hari (Tabel 4). Nilai $\mathrm{pH}$ pada formulasi NLC berkisar antara 6,32 sd. 6,47, yang menunjukkan nilai $\mathrm{pH}$ mendekati netral. Hal tersebut dikarenakan komposisi bahan yang digunakan dalam sistem NLC adalah air dengan konsentrasi yang 
paling besar dalam sistem NLC memiliki pH netral (7), PS dan PO memiliki kisaran pH 6,0 sd. 6,5 dan surfaktan Tween 80 memiliki pH 6. Perbedaan konsentrasi pada formulasi pada sistem NLC menunjukkan nilai $\mathrm{pH}$ yang tidak berbeda nyata. Pengukuran viskositas dilakukan untuk mengetahui tingkat kekentalan sistem NLC, viskositas formulasi sistem NLC berkisar pada $18 \mathrm{sd} .26$ cP. Kisaran nilai viskositas sistem NLC tergantung pada komposisi bahan yang digunakan, terutama jenis lipid dan surfaktan yang digunakan. Lipid dan surfaktan mempengaruhi tingkat viskositas sampel, lipid yang memiliki densitas rendah dapat berpengaruh pada kestabilan sistem, yang memungkinkan terjadinya creaming, flocculation, dan coalescense. Hasil penelitian menunjukkan semakin meningkatnya konsentrasi lipid meningkatkan nilai viskositas, yang seiring dengan penelitian Müller et al. (2002). Menurut van Dijke et al. (2010) semakin meningkat viskositas sistem semakin tinggi stabilitasnya, hal tersebut dikonfirmasi juga pada uji stabilitas penggunaan surfaktan yang meningkat menunjukkan bagusnya tingkat kestabilan pada sistem.

\section{Ukuran partikel, PDI, dan Zeta Potensial}

NLC stabil dilakukan analisa ukuran partikel, PDI, dan ZP (Tabel 4). Ukuran partikel NLC pada 0 hari berkisar $160 \mathrm{sd}$. $298 \mathrm{~nm}$ dan setelah penyimpanan pada suhu ruang selama 30 hari berkisar $176 \mathrm{sd}$. $342 \mathrm{~nm}$. Terjadi sedikit peningkatan ukuran partikel sitem NLC setelah disimpan selama 30 hari, namun peningkatan ukuran masih dalam skala nano dan masih dalam kondisi stabil, hal tersebut dapat disebabkan karena adanya terjadinya penggabungan partikel selama penyimpanan. Lv et al. (2016) melaporkan NLC Brucea javanica oil mengalami sedikit peningkatan ukuran partikel dari 181,5 menjadi $195 \mathrm{~nm}$ setelah disimpam 30 hari yang sebagian terjadi karena adanya agregasi partikel selama penyimpanan. Selain itu dengan ukuran partikel nano memiliki luas permukaan spesifik yang besar, yang dapat berpengaruh pada peningkatan bioavailabilitas senyawa bioaktif pada pencernaan. Sistem NLC yang memiliki ukuran pada kisaran 100 sd. $600 \mathrm{~nm}$ yang memiliki potensi penyerapan yang baik dalam saluran gastrointestinal manusia (Weiss et al., 2008).

PDI menggambarkan tingkat keseragaman pada suatu sistem, dimana semakin kecil nilai PDI maka distribusi partikel dalam suatu sistem monodispersi lebih seragam (Luo et al., 2017). Sampel dengan nilai PDI mendekati 0 menunjukkan sampel monodispersi, sedangkan nilai PDI < 1 menunjukkan sampel polidispersi (Danaei et al., 2018). Nilai PDI sistem NLC 0,21 sd. 0,56 (0 hari) dan 0,23 sd. 0,54 (30 hari) menunjukkan tidak adanya perubahan yang berarti pada nilai PDI sistem NLC setelah penyimpanan. ZP menggambarkan muatan partikel yang terdapat pada permukaan suatu sistem koloid, selain itu digunakan untuk memprediksi stabilitas fisik sistem jangka panjang. Nilai ZP lebih dari $+25 \mathrm{mV}$ atau $-25 \mathrm{mV}$ memiliki stabilitas yang tinggi. Hasil penelitian menunjukkan nilai zeta potensial adalah negatif dengan nilai ZP pada sampel NLC berkisar $-21,25 \pm 0,01 \mathrm{sd}$. $-33,70 \pm 0,44 \mathrm{mV}$.
Nilai tersebut mengindikasi tolakan listrik (electric repulsion), dan memiliki stabilitas sistem dispersi yang baik dan dipengaruhi oleh adanya surfaktan Twen 80 (How et al., 2011). Sampel NLC yang stabil ditunjukkan pada Gambar 1, sedangkan morfologi NLC yang ditentukan dengan TEM ditunjukkan pada Gambar 2 yang memperlihatkan bentuk morfologi partikel bulat dan seragam.

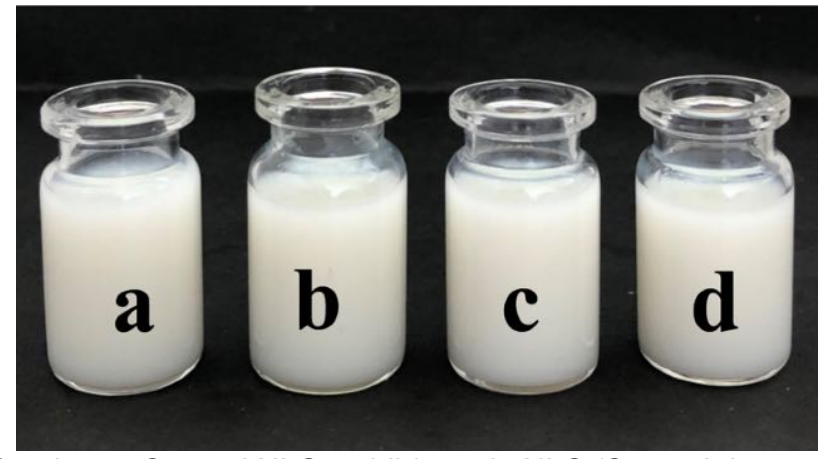

Gambar 1. Sampel NLC stabil formula NLC (Sampel dengan rasio lipid surfaktan (1:4); (lipid+surfaktan)/air (70\%), dan rasio lipid padat:lipid cair $(9: 1,8: 2,7: 3$, dan $6: 4$, yang masingmasing ditunjukkan dengan huruf $a, b, c, d$ )

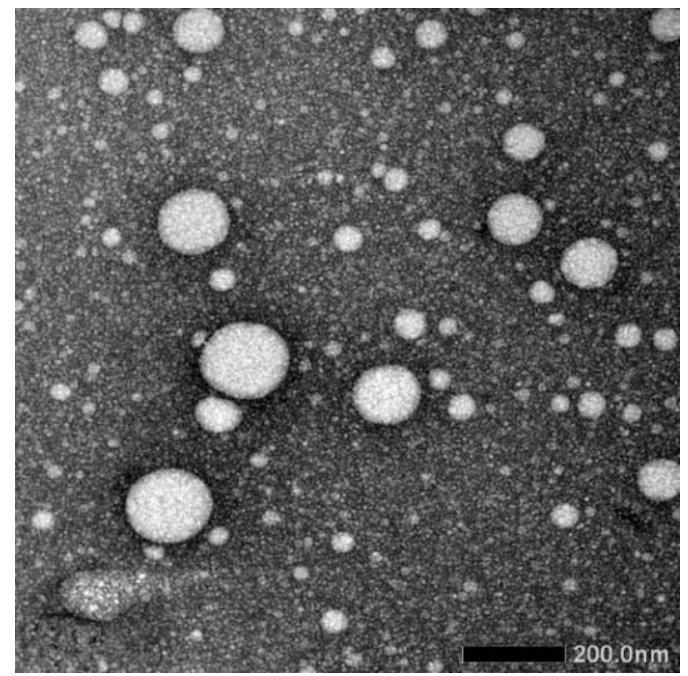

Gambar 2. Morfologi NLC dengan TEM pada formula F5B (Rasio lipid pada:lipid cair (8:2); rasio lipid:surfaktan (1:4); rasio (lipid+surfaktan)/air (70\%)

Berdasarkan proses formulasi yang dilakukan pada penelitian ini, pengujian stabilitas dan karakterisasi sistem NLC memberikan informasi bahwa PS dan PO merupakan jenis lipid yang dapat dikembangkan dan diaplikasikan sebagai sistem pembawa untuk komponen bioaktif lipofilik, salah satunya sebagai ingredient pangan fungsional. Formulasi yang dapat disarankan untuk dipilih adalah formulasi yang menggunakan surfaktan Tween 80 lebih sedikit, dengan pertimbangan untuk memperoleh sifat sensoris yang lebih baik, selain itu didasarkan pada LD50 dari Tween 80 yaitu 25 mg/kg (Rowe, 2009). Namun secara keseluruhan formula NLC stabil yang dihasilkan jauh daripada batas LD50. Informasi data pada penelitian ini dapat digunakan sebagai dasar untuk mendapatkan formula yang benarbenar optimal sesuai dengan komponen bioaktif yang diinginkan, salah satunya dengan teknik optimasi. 


\section{Kesimpulan}

Sistem NLC berhasil dibuat dari campuran lipid PS dan PO serta surfaktan Tween 80 dengan menghasilkan formula yang stabil pada rasio lipid padat:lipid cair $5: 5$ sd. 9:1, rasio lipid: surfaktan 1:4 sd. $1: 5$, rasio lipid+surfaktan/air $65,70,75$, dan $80 \%$, dan dapat teridentifikasi karakter fisiknya.

\section{Ucapan Terimakasih}

Penelitian ini didanai oleh Kementerian Riset, Teknologi, dan Pendidikan Tinggi, Republik Indonesia, yang dikelola oleh Universitas Gadjah Mada melalui skema Penelitian Terapan Unggulan Perguruan Tinggi Tahun 2018.

\section{Daftar Pustaka}

Babazadeh, A., Ghanbarzadeh, B., Hamishehkar, H. 2017. Formulation of food grade nanostructured lipid carrier (NLC) for potential applications in medicinal-functional foods. Journal of Drug Delivery Science and Technology 39:50-58. DOI:10.1016/j.jddst.2017.03.001.

Bagherpour, S., Alizadeh, A., Ghanbarzadeh, S., Mohammadi, M., Hamishehkar, H. 2017. Preparation and characterization of Betasitosterolloaded nanostructured lipid carriers for butter enrichment. Food Bioscience 20:51-55. DOI:10.1016/j.fbio.2017.07.010.

Danaei, M., Dehghankhold, M., Ataei, S., Hasanzadeh Davarani, F., Javanmard, R., Dokhani, A., Mozafari, M. 2018. Impact of particle size and polydispersity index on the clinical applications of Ipidic nanocarrier systems. Pharmaceutics 10(2):2-17. 10020057 .

Fathi, H. A., Allam, A., Elsabahy, M., Fetih, G., El-Badry, M. 2018. Nanostructured lipid carriers for improved oral delivery and prolonged antihyperlipidemic effect of simvastatin. Colloids and Surfaces B: Biointerfaces 162:236-245. DOI:10.1016/j.colsurfb.2017.11.064.

Han, F., Li, S., Yin, R., Liu, H., Xu, L. .2008. Effect of surfactants on the formation and characterization of a new type of colloidal drug delivery system: nanostructured lipid carriers. Colloids and Surfaces A: Physicochemical and Engineering Aspects 1-3(315):210-216. DOI:10.1016/ j.colsurfa.2007.08.005.

How, C. W., Rasedee, A., Abbasalipourkabir, R. 2013. Characterization and cytotoxicity of nanostructured lipid carriers formulated with olive oil, hydrogenated palm oil, and polysorbate 80 . IEEE Transactions on Nanobioscience 12(2):7278. DOI:10.1109/TNB.2012.2232937.

How, C. W., Abdullah, R., Abbasalipourkabir, R. 2011. Physicochemical properties of nanostructured lipid carriers as colloidal carrier system stabilized with polysorbate 20 and polysorbate. African Journal of Biotechnology 10(9):1684-1689. DOI: 10.5897/AJB10.1667.
Hu, F. Q., Jiang, S. P., Du, Y. Z., Yuan, H., Ye, Y. Q., Zeng, S. 2006. Preparation and characteristics of monostearin nanostructured lipid carriers. International Journal of Pharmaceutics 314(1):8389. DOI:10.1016/j.ijpharm.2006.01.040.

Hung, L. C., Basri, M., Tejo, B. A., Ismail, R., Nang, H. L. L., Hassan, H. A., May, C. Y. 2011. An improved method for the preparations of nanostructured lipid carriers containing heat-sensitive bioactives. Colloids and Surfaces B: Biointerfaces 87(1):180186. DOI:10.1016/j.colsurfb.2011.05.019.

Karn-orachai, K., Smith, S. M., Phunpee, S., Treethong, A., Puttipipatkhachorn, S., Pratontep, S., Ruktanonchai, U. R. 2014. The effect of surfactant composition on the chemical and structural properties of nanostructured lipid carriers. Journal of Microencapsulation 31(6): 609-618. DOI: 10.3109/02652048.2014.911374.

Lesmes, U., McClements, D. J. 2009. Structurefunction relationships to guide rational design and fabrication of particulate food delivery systems. Trends in Food Science and Technology 20(10):448-457. DOI:10.1016/j.tifs.2009.05.006.

Liu, Y., Wang, L., Zhao, Y., He, M., Zhang, X., Niu, M., Feng, N. 2014. Nanostructured lipid carriers versus microemulsions for delivery of the poorly water-soluble drug luteolin. International Journal of Pharmaceutics 476(1-2):169-177. DOI: 10.1016/j.ijpharm.2014.09.052.

Luo, X., Zhou, Y., Bai, L., Liu, F., Deng, Y., McClements, D. J. 2017. Fabrication of $\beta$-carotene nanoemulsion-based delivery systems using dualchannel microfluidization: Physical and chemical stability. Journal of Colloid and Interface Science 490:328-335. DOI:10.1016/j.jcis.2016.11.057.

Lv, W., Zhao, S., Yu, H., Li, N., Garamus, V. M., Chen, Y., Zou, A. 2016. Brucea javanica oil-loaded nanostructure lipid carriers (BJO NLCs): Preparation, characterization and in vitro evaluation. Colloids and Surfaces A: Physicochemical and Engineering Aspects 504:312-319. DOI:10.1016/j.colsurfa. 2016.05.068.

McClements, D. J. 2010. Emulsion design to improve the delivery of functional lipophilic components. Annual Review of Food Science and Technology 1:241-269. DOI:10.1146/annurev.food.080708. 100722.

McClements, D. J. 2017. The future of food colloids: Next-generation nanoparticle delivery systems. Current Opinion in Colloid and Interface Science 28:7-14. DOI:10.1016/j.cocis.2016.12.002.

McClements, D. J., Rao, J. 2011. Food-grade nanoemulsions: formulation, fabrication, properties, performance, biological fate, and potential toxicity. Critical Reviews in Food Science and Nutrition 51(4):285-330. DOI:10.1080/10408398.2011.559558.

Mohanraj, V. J., Chen, Y. 2007. Nanoparticles: A review. Tropical Journal of Pharmaceutical Research 5(1):561-573. DOI:10.4314/tjpr.v5i1.14634. 
Müller, R. H., Radtke, M., Wissing, S. A. 2002. Solid lipid nanoparticles (SLN) and nanostructured lipid carriers (NLC) in cosmetic and dermatological preparations. Advanced Drug Delivery Reviews 54:S131-S155. DOI:10.1016/S0169-409X(02) 00118-7.

Okonogi, S., Riangjanapatee, P. 2015. Physicochemical characterization of lycopeneloaded nanostructured lipid carrier formulations for topical administration. International Journal of Pharmaceutics 478(2):726-735. DOI:10.1016/ j.ijpharm.2014.12.002.

Pantzaris, T. P., Sue, T. T. 2017. Pocketbook of oil palm uses (Seventh Ed). Selangor, Malaysia: Malaysian Palm Oil Board (MPOB).

Pardeike, J., Weber, S., Haber, T., Wagner, J., Zarfl, H. P., Plank, H., Zimmer, A. 2011. Development of an itraconazole-loaded nanostructured lipid carrier (NLC) formulation for pulmonary application. International Journal of Pharmaceutics 419(12):329-338. DOI:10.1016/j.ijpharm.2011.07.040.

Prieto, C., Calvo, L. 2013. Performance of the biocompatible surfactant Tween 80 , for the formation of microemulsions suitable for new pharmaceutical processing. Journal of Applied Chemistry:1-10. DOI:10.1155/2013/930356.

Rowe, R. C. (Ed.). 2009. Handbook of pharmaceutical excipients (6. ed). London: APhA, (PhP) Pharmaceutical Press.

Severino, P., Santana, M. H. A., Souto, E. B. 2012. Optimizing SLN and NLC by 22 full factorial design: effect of homogenization technique. Materials Science and Engineering: C 32(6):1375-1379. DOI:10.1016/j.msec.2012. 04.017.

Shah, N. V., Seth, A. K., Balaraman, R., Aundhia, C. J., Maheshwari, R. A., Parmar, G. R. 2016. Nanostructured lipid carriers for oral bioavailability enhancement of raloxifene: Design and in vivo study. Journal of Advanced Research 7(3):423434. DOI:10.1016/j.jare.2016.03.002.
Tamjidi, F., Shahedi, M., Varshosaz, J., Nasirpour, A. 2013. Nanostructured lipid carriers (NLC): A potential delivery system for bioactive food molecules. Innovative Food Science and Emerging Technologies 19:29-43. DOI:10.1016/ j.ifset.2013.03.002.

van Dijke, K., Kobayashi, I., Schroën, K., Uemura, K., Nakajima, M., Boom, R. 2010. Effect of viscosities of dispersed and continuous phases in microchannel oil-in-water emulsification. Microfluidics and Nanofluidics 9(1):77-85. DOI:10.1007/s10404-009-0521-7.

Weiss, J., Decker, E. A., McClements, D. J., Kristbergsson, K., Helgason, T., Awad, T. 2008. Solid Lipid Nanoparticles as delivery systems for bioactive food components. Food Biophysics 3(2):146-154. DOI:10.1007/s11483-008-9065-8.

Witayaudom, P., Klinkesorn, U. 2017. Effect of surfactant concentration and solidification temperature on the characteristics and stability of nanostructured lipid carrier (NLC) prepared from rambutan ( Nephelium lappaceum L.) kernel fat. Journal of Colloid and Interface Science, 505:1082-1092. DOI:10.1016/j.jcis.2017.07.008.

Zheng, M., Falkeborg, M., Zheng, Y., Yang, T., Xu, X. 2013. Formulation and characterization of nanostructured lipid carriers containing a mixed lipids core. Colloids and Surfaces A: Physicochemical and Engineering Aspect 430:7684. DOI:10.1016/j.colsurfa.2013.03.070.

Zhu, J., Zhuang, P., Luan, L., Sun, Q., Cao, F. 2015. Preparation and characterization of novel nanocarriers containing krill oil for food application. Journal of Functional Foods 19:902912. DOI:10.1016/j.jff.2015.06.017.

Ziani, K., Fang, Y., McClements, D. J. 2012. Fabrication and stability of colloidal delivery systems for flavor oils: Effect of composition and storage conditions. Food Research International 1(46):209-216. DOI:10.1016/j.foodres.2011.12.017. 